\title{
The hydroid Tubularia larynx causing 'bloom' of the ascidians Ciona intestinalis and Ascidiella aspersa
}

\author{
Günter H. Schmidt*
}

Department of Zoology, University of Reading, Whiteknights, Reading RG6 2AJ, United Kingdom

ABSTRACT: A canopy of the hydroid Tubularia larynx formed on fouling panels greatly enhanced settlement of the ascidians Ciona intestinalis and Ascidiella aspersa, which subsequently monopolized the entire substratum. The results would explain the occurrence of ascidian 'blooms', and interspecific interactions should therefore be taken into account before population outbursts can be correlated to eutrophication and other environmental factors.

The solitary ascidians Ciona intestinalis and Ascidiella aspersa are important sessile epibenthos in nearshore sublittoral areas (Millar, 1971). As prominent fouling species they are also widely distributed in many harbours (Woods Hole Oceanic Institution, 1952; Millar, 1971). Being short-lived species, their population densities in temperate waters follow seasonal patterns related to reproduction, growth, and mortality. Little is known, however, regarding the often sharp fluctuations in abundance which may lead to sudden 'blooms' of these and other solitary ascidians (Millar, 1971 for references; Gulliksen, 1980; Riggio et al., 1980). Data are presented from a fouling study showing that the hydroid Tubularia larynx greatly enhanced settlement of $C$. intestinalis and $A$. aspersa, which subsequently monopolized the entire substratum.

Black perspex panels measuring $0.25 \times 0.25 \mathrm{~m}$ were horizontally aligned and suspended from a raft in Langstone Harbour, Hampshire, U. K. (see Schmidt, 1982). They were submerged in August 1980 and 1981, and collected at intervals varying between 6 and $16 \mathrm{wk}$. Lower sides only were considered.

In 1981, after 6 wk exposure Tubularia larynx covered about $20 \%$ of the panel surface, forming dense growths among which Ciona intestinalis and

\footnotetext{
- Present address: Institute of Cancer Research: Royal Cancer Hospital, The Haddow Laboratories, Clifton Avenue, Sutton, Surrey SM 25 PX, United Kingdom
}

Ascidiella aspersa had settled at high frequencies; of 263 ascidians 240 were found among the hydroid (Fig. 1). In 1980, T. larynx recruitment was almost lacking during that period $(<0.5 \%$ cover), and no settlement of the 2 ascidians was recorded. Other species, particularly the barnacle Elminius modestus and colonial ascidians, occurred at comparable frequencies. A parallel series in which vertically aligned panels were individually screened with different cage types showed that in both years larvae of $C$. intestinalis and $A$. aspersa were equally available for colonization, heavy settlement being found on all caged substrata; there was no indication of predation on the 2 species (Schmidt and Warner, in prep.). The results thus suggest that the canopy of $T$. larynx greatly enhanced recruitment of the 2 solitary ascidians, probably by making the panel surface more attractive for settlement through current reduction and light attenuation. In 1980, several months after submergence, the panel community was dominated by E. modestus and colonial ascidians, while in 1981, $C$. intestinalis and $A$. aspersa covered all available space (Fig. 2).

Increased abundance of solitary ascidians under hydroid canopies has been documented in other fouling studies (Sutherland, 1974; Standing, 1976; Dean and Hurd, 1980) but only Dean and Hurd (1980) and Dean (1981) suggested that hydroids may have facilitated settlement of ascidians.

Dense canopies of Tubularia larynx and other hydroids are often short-lived. In environmental monitoring programmes it may therefore not be easy to recognize the successional sequence that may have led to an observed ascidian 'bloom'. As a widely distributed, readily-identified species, Ciona intestinalis would be a valuable indicator species for marine polution studies (cf. Dalby et al., 1979). Sharp population changes may be attributed to changes in the level of 

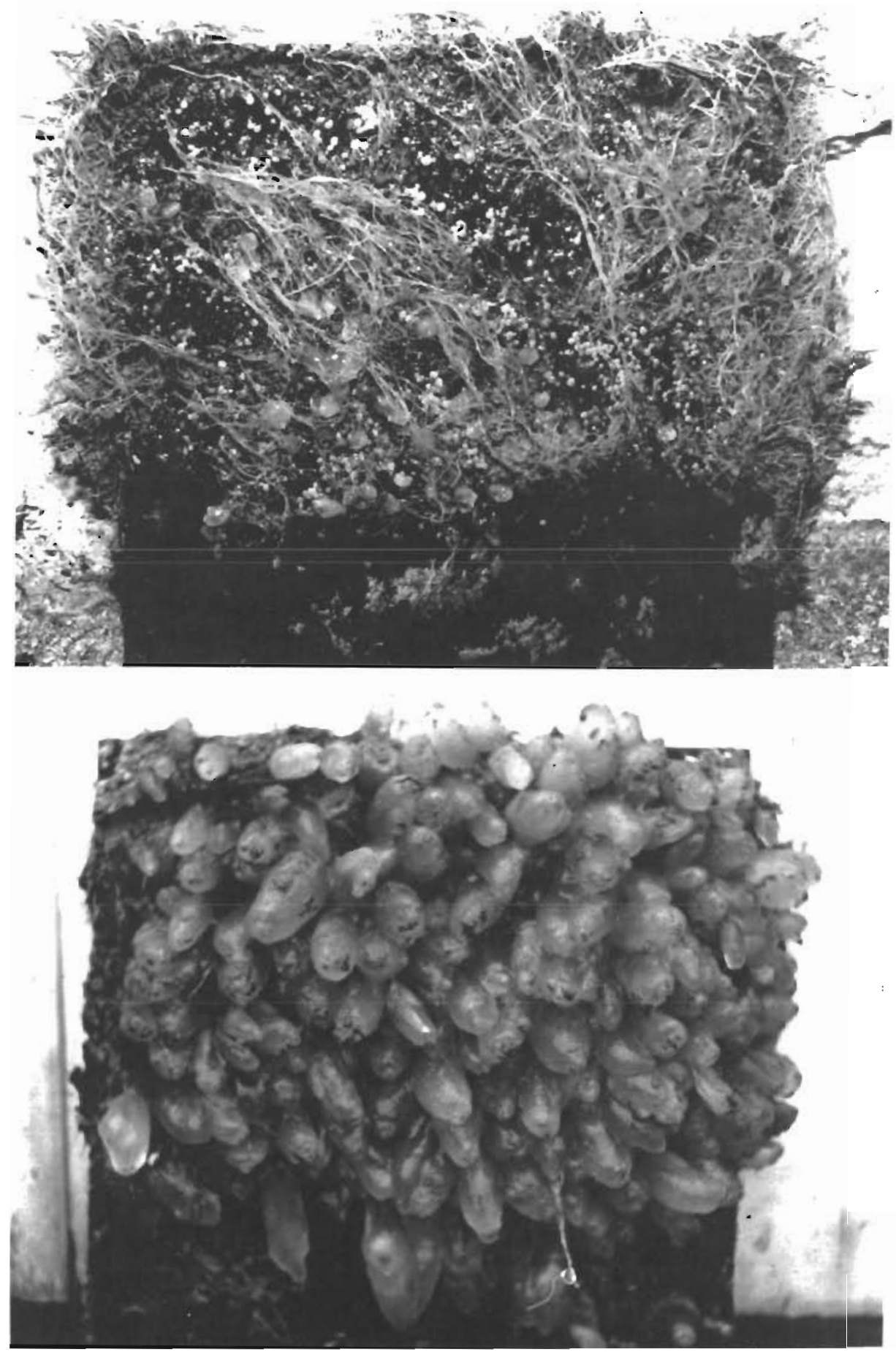

Fig. 1. Horizontal lower surface of a panel submerged 27th August 1981 until 7 th October 1981 The hydroid Tubularia larynx grew densely, the ascidians Ciona intestinalis and Ascidiella aspersa had settled abundantly in the understore. The barnacle Elminius modestus appears as white speckels on the photograph. The lower, bare part of the panel was the attachment area to the frame of the raft. Panel size: $0.25 \times 0.25 \mathrm{~m}$ eutrophication, particularly in harbours (Riggio et al., 1980) but any 'abnormal' fluctuations should be carefully assessed against other possible causes, such as interspecific interactions.

Acknowledgements. I would like to thank Dr. G. F. Warner for encouragement and critical reading of the manuscript. I am also indebted to the Ministry of Defence (Navy) Exposure Trials Station (ETS), Portsmouth, for the use of facilities and help with the field work. The study was carried out during the tenure of a Postgraduate Studentship awarded by the University of Reading.

Fig. 2. The community as shown in Fig. 1 developed to a 'bloom' of Ciona intestinalis and Ascidiella aspersa (16th December 1.981)

\section{LITERATURE CITED}

Dalby, D. H., Cowell, E. B., Syratt, W J. (1979). Biologicai monitoring around an oil refinery. In: Nichols, D. (ed.) Monitoring the marine environment. Institute of Biology, London, p. 141-152 
Dean, T. A. (1981). Structural aspects of sessile invertebrates as organizing forces in an estuarine fouling community. $J$. exp. mar. Biol. Ecol. 53; 163-180

Dean, T. A., Hurd, L. E. (1980). Development in an estuarine fouling community: the influence of earlier colonists on later arrivals. Oecologia (Berl.) 46: 295-301

Gulliksen, B. (1980). The macrobenthic rocky-bottom fauna of Borgenfjorden, North-Tröndelag, Norway. Sarsia 65: $115-138$

Millar, R. H. (1971). The biology of ascidians. Adv. mar. Biol. 9: $1-100$

Riggio, S., Genchi, G., Lugaro, A., Di Pisa, G. (1980). Basic data for a model of a harbour ecosystem: the harbour of Palermo (Sicily). In: Moroni, A. (ed.) Atti $1^{\circ}$ Congresso S.

IT, E. - Società Italiana di Ecologia, p. 548
Schmidt, G. H. (1982). Random and aggregative settlement in some sessile marine invertebrates. Mar. Ecol. Prog. Ser. 9: $97-100$

Standing, J. D. (1976). Fouling community structure: effects of the hydroid, Obelia dichotoma, on larval recruitment. In: Mackie, G. O. (ed.) Coelenterate ecology and behavior. Plenum Press, New York, p. 155-164

Sutherland, J. P. (1974). Multiple stable points in natural communities. Am. Nat. 108: 859-873

Woods Hole Oceanographic Institution (1952). Marine fouling and its prevention. United States Naval Institute, Annapolis, Maryland 